\title{
Exponential Reaching Law and Sensorless DTC IM Control with Neural Network Online Parameters Estimation Based on MRAS
}

\author{
Legrioui Said, Rezgui Salah Eddine, Benalla Hocine \\ Electrotechnic Department, Faculty of Sciences of Technology, Univercity of Mentouri's brothers of Constantine
}

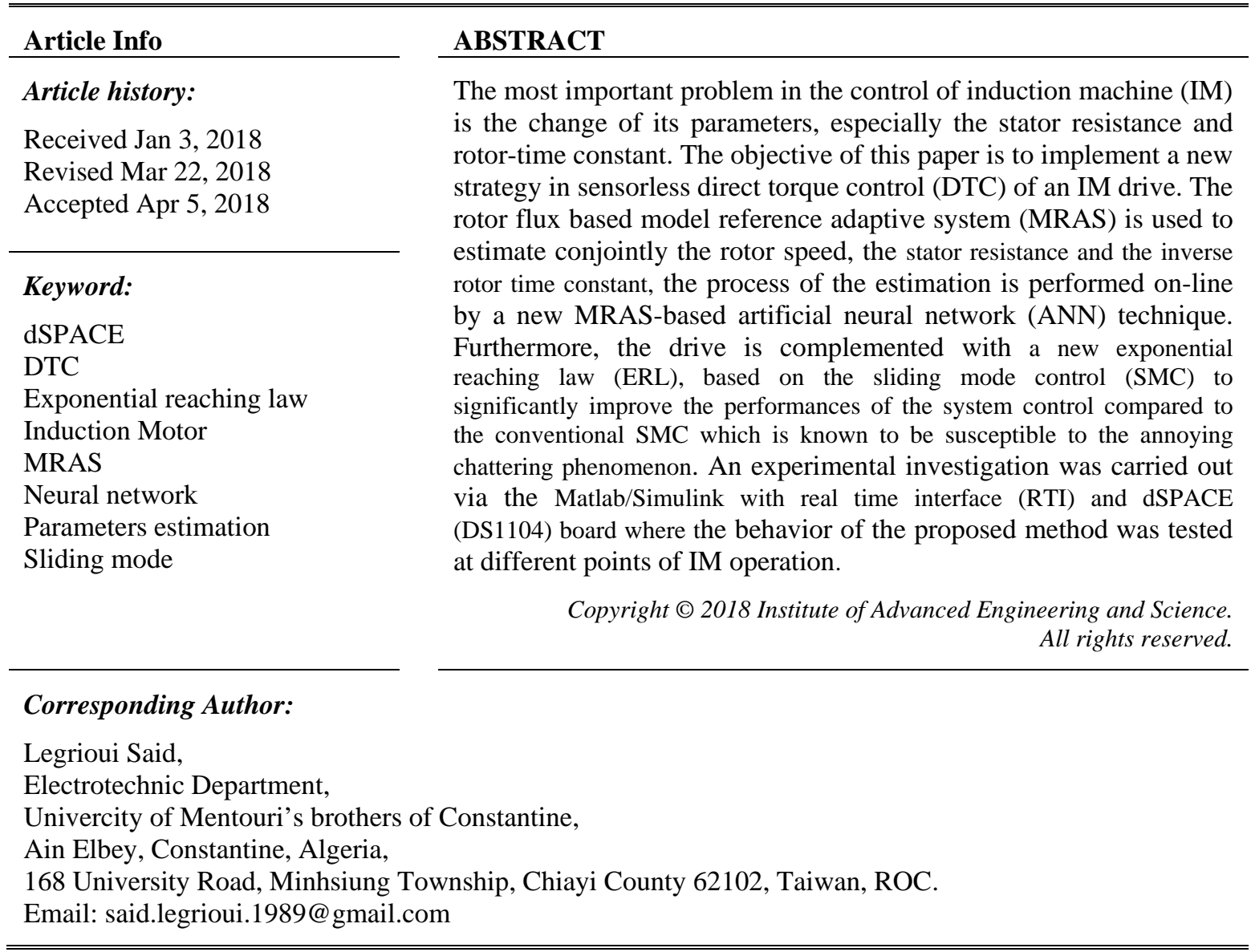

\section{INTRODUCTION}

The DTC method is based on a direct control of the electromagnetic torque and stator flux of the induction machine. This technique was firstly introduced by I. Takahashi and T. Noguchi in the mid eighties [1], [2] in order to give an alternative control to the existing vector control. The DTC has excellent torque response, but it causes many oscillations due to the control of the flux and the torque through hysteresis band controllers, which influence its performance and implementation [3]. For economical and technical reasons it is preferable to remove the sensor of the rotor speed. Several strategies have been proposed in order to estimate the rotor speed in the IM sensorless drive. Among these techniques, the model reference adaptive system (MRAS) is one of the most commonly used techniques mainly to its relative simplicity and low computational effort [2], [4], [5], [6].

The reactive power MRAS-based is robust against the variation of the stator resistance while avoiding pure integration, but suffers from a problem of instability, therefore the rotor flux MRAS-based proposed by Schauder [7] is the most popular strategy of MRAS techniques, and much work has been done on improving the performance of this strategy. In general, the main problems of the sensorless control are 
operating at low speed, the problems of sensitivity and the variation of parameters of the induction machine, specifically, the stator resistance and the rotor-time constant, with also the integration problems [8], [9]. For any estimation-based model, the problems are localized at low speeds, because the voltages induced in the rotor are very small and disappear at zero stator frequency [9], and stator voltage drop becomes influent, thus the determination of the stator resistance is required for good implementation of the drive. On the other hand, the rotor-time constant is required in the MRAS for estimating the rotor speed. These parameters have the most significant effect on the accuracy of the speed estimation; their precise knowledge is of paramount importance to obtain a good speed control.

The proportional integral (PI) controllers are widely used in the application of industrial control systems. They have a simple structure and can provide a satisfactory performance in a wide operation range. Therefore, the most adaptive systems described for observers MRAS acquirer linear PI regulator for generating the estimated speed, but due to the variation of the parameters of the induction machine mainly related to the heating of the machine and integration drift problems, we have introduced new types of controllers based on sliding mode in the speed regulation and artificial neuron network thechnique for the conjoint estimation of the most time-varing parameters for his simplisite and the ease of implementation compared to the other methods.

From these methods, the sliding mode control initially investigated for electric motors by Utkin [10] has the finest results that lead to the step up of IM control. In the other hand, this type of controllers has a big chattering problem [6]. Therfore, a new theory called Reaching Law Control method (RLC) has been introduced in this sliding mode controller and many researchers have been conducted in this way. In RLC method the error dynamics is specified in the reaching mode, with selecting appropriately the parameters both, the dynamic quality of the SMC system can be controlled and the chattering is uninvolved [11].

In this paper, we propose to replace the conventional PI controllers used in the speed regulation by a new exponential reaching law (ERL) technique based on sliding mode controller. Then, we propose a conjoint on-line estimation of the stator resistance and the inverse of rotor time constant by one block of artificial neural network technique based on sensorless MRAS-DTC control.

\section{DIFFERENTIAL EQUATIONS OF THE STATE MODEL}

The DTC is built in a steady state. It does not need the stator angle, so the state model equations will be written taking into consideration the stator currents $I_{s \alpha}, I_{s \beta}$ and, the rotor flux $\varphi_{r \alpha}, \varphi_{r \beta}$ as state variables as shown in (1)

$$
\left\{\begin{aligned}
\frac{d I_{s \alpha}}{d t}=- & \frac{1}{\sigma L_{s}}\left(R_{s}+\frac{R_{r} M^{2}}{L^{2} r}\right) I_{s \alpha}+\frac{1}{\sigma L_{s}}\left(\frac{R_{r} M}{L_{r}^{2}}\right) \varphi_{r \alpha} \\
& \quad+\frac{1}{\sigma L_{s}}\left(\frac{M}{L_{r}}\right) \omega \varphi_{r \beta}+\frac{1}{\sigma L_{s}} V_{s \alpha} \\
\frac{d I_{s \beta}}{d t}=- & \frac{1}{\sigma L_{s}}\left(R_{s}+\frac{R_{r} M^{2}}{L^{2} r}\right) I_{s \beta}+\frac{1}{\sigma L_{s}}\left(\frac{R_{r} M}{L_{r}^{2}}\right) \varphi_{r \beta} \\
& \quad-\frac{1}{\sigma L_{s}}\left(\frac{M}{L_{r}}\right) \omega \varphi_{r \alpha}+\frac{1}{\sigma L_{s}} V_{s \beta} \\
\frac{d \varphi_{r \alpha}}{d t}= & \frac{R_{r} M}{L_{r}} I_{s \alpha}-\frac{R_{r}}{L_{r}} \varphi_{r \alpha}+\omega_{s l} \varphi_{r \beta} \\
\frac{d \varphi_{r \beta}}{d t}= & \frac{R_{r} M}{L_{r}} I_{s \beta}-\frac{R_{r}}{L_{r}} \varphi_{r \beta}-\omega_{s l} \varphi_{r \alpha}
\end{aligned}\right.
$$

Where $R_{s}$ and $R_{r}$ are the stator and rotor resistances, $L_{s}$ and $L_{r}$ are the stator and rotor inductances, $L_{m}$ is the mutual inductance and $=1-\frac{M^{2}}{L_{s} L_{r}}$. The mechanical equation (2) is:

$$
J \frac{d \Omega}{d t}=T_{e}-T_{r}-f_{v} \Omega
$$

Where $J$ is the moment of inertia, $T_{e}$ and $T_{r}$ are the electromagnetic and load torques, $f_{v}$ is the viscous friction coefficient, and $\Omega$ is the mechanical rotor speed.

\section{THE DTC WITH SLIDING MODE SPEED CONTROL}

\subsection{Theory of DTC and sliding mode with ERL}

The direct control of the torque and flux is based on the error between the reference values and the estimated values of the torque and flux; it is possible to control the states of the inverter to reduce errors 
directly in the band limits of the predetermined hysteresis controller. The stator flux and the electromagnetic torque of the machine are obtained from (3-4):

$$
\begin{aligned}
& \left\{\begin{array}{l}
\frac{d}{d t} \varphi_{s}=V_{s}-R_{s} * I_{s} \\
\varphi_{s}=\varphi_{s 0}+\int_{0}^{t}\left(V_{s}-R_{s} * I_{s}\right) d t
\end{array}\right. \\
& T_{e}=p_{p}\left(\varphi_{s \alpha} I_{s \beta}-\varphi_{s \beta} I_{s \alpha}\right.
\end{aligned}
$$

With $p_{p}$ is the poles pair number. This is to keep the two quantities within the hysteresis band. In addition, the voltage vector applied in each switching time is obtained at the output of this regulator with the help of the Takahashi table [1].

In sliding mode control the trajectory of the system is conducted toward a sliding surface and kept on it by means of a suitable switching logic until it reach the equilibrium [10]. The conditions of convergence enable the dynamic system to converge to the sliding surfaces $S(x)$. Two conditions are noted wich correspond to the reaching mode of the system state [11] as shown in (5).

$$
S(x) \dot{S}(x)<0
$$

This is to make a positive scalar function $V(x)>0$ for the state variables of the system. This function is typically used to ensure the stability of nonlinear systems. Defining the Lyapunov's function by (6):

$$
V(x)=\frac{1}{2} S^{2}(x)
$$

To check the reaching condition on the sliding surface, the classical reaching law proposed in sliding mode control is presented as shown in (7):

$$
\dot{S}=-k \operatorname{sign}(S), k>0
$$

The time required for the system to attain the sliding surface, called reaching time $t_{r}$ is (8):

$$
t_{r}=\frac{\left|S_{0}\right|}{k}
$$

As in [18], the suggested reaching law is based on the choice of an exponential expression that adapts with the changes of the switching function. This exponential reaching law is presented as shown in (9-10):

$$
\begin{aligned}
& \dot{S}=-\frac{k}{N(S)} \operatorname{sign}(S), \quad k>0 \\
& N(S)=\theta_{0}+\left(1-\theta_{0}\right) e^{-\alpha|S|^{P}}
\end{aligned}
$$

$\theta_{0}$ Is a strongly positive offset smaller than one, $p$ and $\alpha$ are also strictly positive constant. We note that the reaching law presented in (9) does not influence the stability of the control process, because $N(S)$ is strictly positive. From (9), we can observe that if $|S|$ increases for a few reasons, $N(S)$ approaches $\theta_{0}$, hence $\mathrm{k} / \mathrm{N}(\mathrm{S})$ converges to $k / \theta_{0}$, which is larger than $k$, this means that $k / N(S)$ increases, thus enhances the pull of the sliding surface at the same time. In addition, if $|S|$ decreases, $N(S)$ approach one, so $k / N(S)$ converges to k. This can prove that when the system approaches the sliding surface, $k / N(S)$ progressively decreases which limits the chattering when the system attains the sliding surface. Therefore, the suggested reaching law permits the sliding mode controller to dynamically adapt to the change of the switching function by permitting $k / N(S)$ to vary from $\mathrm{k}$ to $k / \theta_{0}$. Note that if $\theta_{0}$ is selected to be identical to one, the reaching law presented in (9) becomes the same reaching law in (7).

\subsection{ERL Sliding mode speed controller}

The SM-ERL speed controller presented in Figure 1 which is transient dynamic response depends on the selection of the sliding surfaces as shown in (11-12).

$$
S(t)=e_{\Omega}(t)-\int_{0}^{t}\left(k_{1}-a\right) e_{\Omega}(t) d(t)
$$




$$
e_{\Omega}(t)=\Omega(t)-\Omega^{*}(t)
$$

Where: $k_{1}$ is a negative constant and $\Omega^{*}$ is the reference rotor speed.

By derivating (12) and using (2), where $f_{1}=T_{r} / J, a=f_{v} / J$ and $b=1 / J$ one can write (13):

$$
\dot{e}_{\Omega}(t)=\dot{\Omega}(t)-\dot{\Omega}^{*}(t)=-a e_{\Omega}(t)+u(t)+d(t)
$$

Where $d(t)$ is the total uncertainties of the parameters $a, b$, and $f_{1}$, and the following terms are lumped in $u(t)$ as shown in (14):

$$
u(t)=b T_{e}(t)-a \Omega^{*}(t)-f_{1}(t)-\dot{\Omega}^{*}(t)
$$

The switching control is chosen as shown in (15-16):

$$
\begin{aligned}
& u(t)=k_{1} e_{\Omega}(t)-K_{\Omega}(S) \operatorname{sign}(S) \\
& K_{\Omega}(S)=\frac{k_{2}}{N(S)}
\end{aligned}
$$

With the assumptions that $k_{2}$ defines the upper bound of the uncertainties $\left(k_{2} \geq|d(t)|, \forall \forall t\right)$, and $\left(k_{1}-a\right)<0$, so the speed tracking error $e_{\Omega}(t)$ tends to zero exponentially as the time tends to infinity. The torque current's reference is given by replacing (15) in (14):

$$
T_{e}^{*}=b^{-1}\left[k_{1} e_{\Omega}-K_{\Omega}(S) \operatorname{sgn}(S)+a \Omega^{*}+\dot{\Omega}^{*}+f_{1}\right]
$$

Additionally, the problem of chattering is handled by using a soft function (18) in the sliding surface neighbourhood, as it's usually done in the variable structure control:

$$
\operatorname{sat}(S)=\left\{\begin{array}{r}
\frac{1}{\varepsilon} S,|S|<\varepsilon \\
\operatorname{sign}(S),|S| \geq \varepsilon
\end{array}\right.
$$

Where the constant factor $\varepsilon$ defines the thickness of the boundary layer and sat is the saturation function.

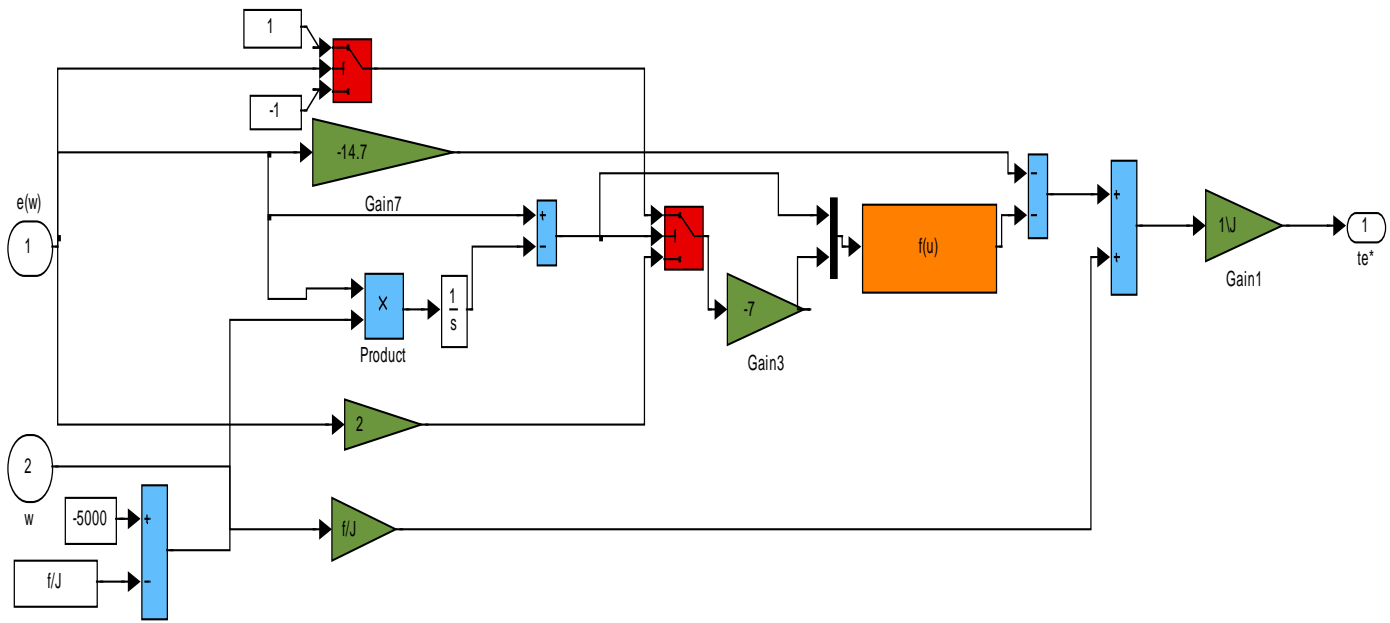

Figure 1. The Simulink diagram of SM-ERL controller

\section{CONJOINT SPEED AND ONLINE ESTIMATION OF PARAMETERS}

By using the rotor-flux based MRAS, the rotor speed, the stator resistance and the rotor-time constant are reconstructed from the reference and the adjustable model [7] presented in Figure 2. 


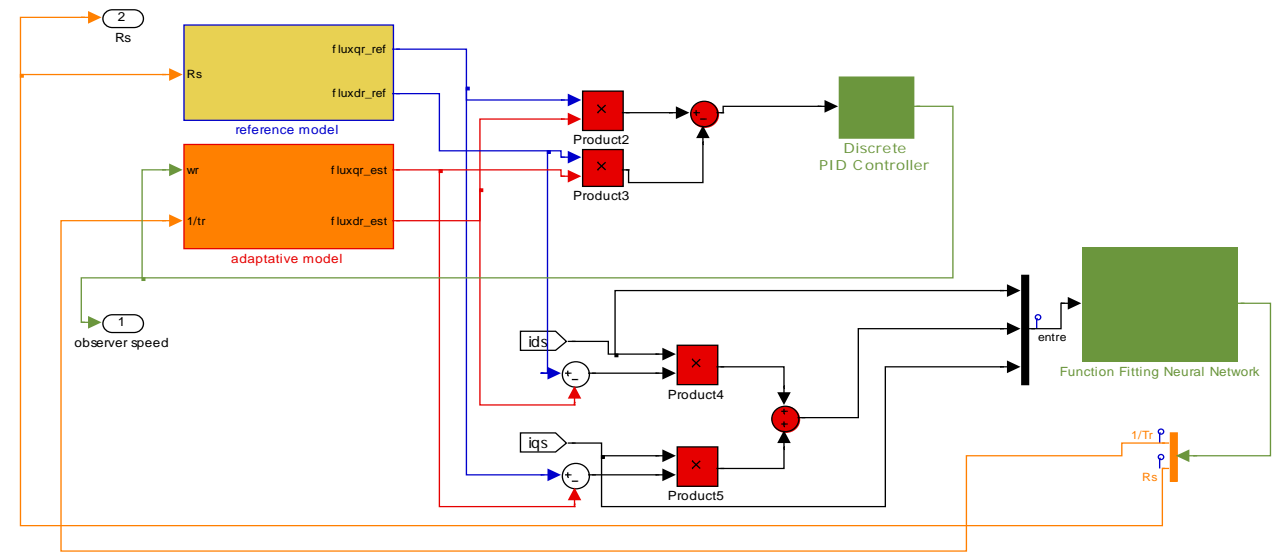

Figure 2. Simulink of MRAS thechnique used

The reference model or the voltage model given by $(19,20)$ generates the rotor flux. The same model is seen as an adjustable model for the online estimation process of the stator resistance [7] [12].

$$
\begin{aligned}
& p \varphi_{r \alpha}=\frac{L_{r}}{M}\left(V_{s \alpha}-\hat{R}_{s} I_{s \alpha}-\delta L_{s} p I_{s \alpha}\right. \\
& p \varphi_{r \beta}=\frac{L_{r}}{M}\left(V_{s \beta}-\hat{R}_{s} I_{s \beta}-\delta L_{s} p I_{s \beta}\right)
\end{aligned}
$$

In the adaptive model, or the current model, the equation describes the components of the rotor flux expressed in terms of stator current components, rotor speed and rotor-time constant. The rotor flux components obtained from the adaptive model are given by (21-22) [7]:

$$
\begin{aligned}
& p \hat{\varphi}_{r \alpha}=\frac{M}{\widehat{T}_{r}} I_{s \alpha}-\frac{1}{\widehat{T}_{r}} \hat{\varphi}_{r \alpha}-\widehat{\omega}_{r} \hat{\varphi}_{r \beta} \\
& p \hat{\varphi}_{r \beta}=\frac{M}{\hat{T}_{r}} I_{s \beta}-\frac{1}{\hat{T}_{r}} \hat{\varphi}_{r \beta}+\widehat{\omega}_{r} \hat{\varphi}_{r \alpha}
\end{aligned}
$$

The MRAS structure proposed in this paper is based on the estimation of the stator resistance, rotortime constant and the rotor speed which is designed upon the concept of hyper stability [13]. In order to make the system asymptotically stable, the proportional-integral controller is used as shown in (23-24):

$$
\begin{aligned}
& \omega_{r}=e_{\omega r}\left(k_{p}+\frac{K_{i}}{p}\right) \\
& e_{\omega_{r}}=\hat{\varphi}_{r \alpha} \varphi_{r \beta}-\hat{\varphi}_{r \beta} \varphi_{r \alpha}
\end{aligned}
$$

The equations of the errors used in the estimation of the stator resistance and the rotor-time constant are given by (25-26) [12] [13]:

$$
\begin{aligned}
& e_{R s}=I_{s \alpha}\left(\varphi_{r \alpha}-\hat{\varphi}_{r \alpha}\right)+I_{s \beta}\left(\varphi_{r \beta}-\hat{\varphi}_{r \beta}\right) \\
& e_{\frac{1}{T r}}=I_{s \alpha}\left(\hat{\varphi}_{r \alpha}-\varphi_{r \alpha}\right)+I_{s \beta}\left(\hat{\varphi}_{r \beta}-\varphi_{r \beta}\right)
\end{aligned}
$$

The adaptation mechanisms which minimize the error between the two models are designed with artificial neural networks. In a neural controller type there are three stages, the first is usually the calculation of the weighted sum of the inputs [14] [15] .The obtained value is compared to a reference value, which is the bias (b). From this value, transfers function calculating the value of the neuron state and the equation as shown in (27). This value will be passed downstream neurons where the output of a neuron is always a scalar [16] [17]. 


$$
y_{i}=f(n)=f\left(\sum w_{i j} x_{i}-b\right)
$$

The network is designed in Matlab (NNtool.) by using a single neural block with three inputs which are $x_{1}=I_{s \alpha}, x_{2}=\left(\varphi_{r \alpha}-\widehat{\varphi}_{r \alpha}\right)+\left(\varphi_{r \beta}-\widehat{\varphi}_{r \beta}\right)$ and $x_{3}=I_{s \beta}$ for the estimation of two parameters $\left(\frac{1}{\widehat{T}_{r}}, \widehat{R}_{s}\right)$. The backpropagation of the error algorithm is used. It consists of two layers: a hidden layer with five neurons, with a hyperbolic tangent activation function (tansig), and an output layer with four neurons, the activation function is linear (purelin). The learning method was made initially by gradient descent (traingd) and then the Levenberg-Marquardt (trainlm).

Finally, we conclude the scheme used in the experimental tests using Matlab Simulink and the RTI blocks of the dSPACE (DS 1104). In Figure 3 is control schema used in simulink and experimental tests.

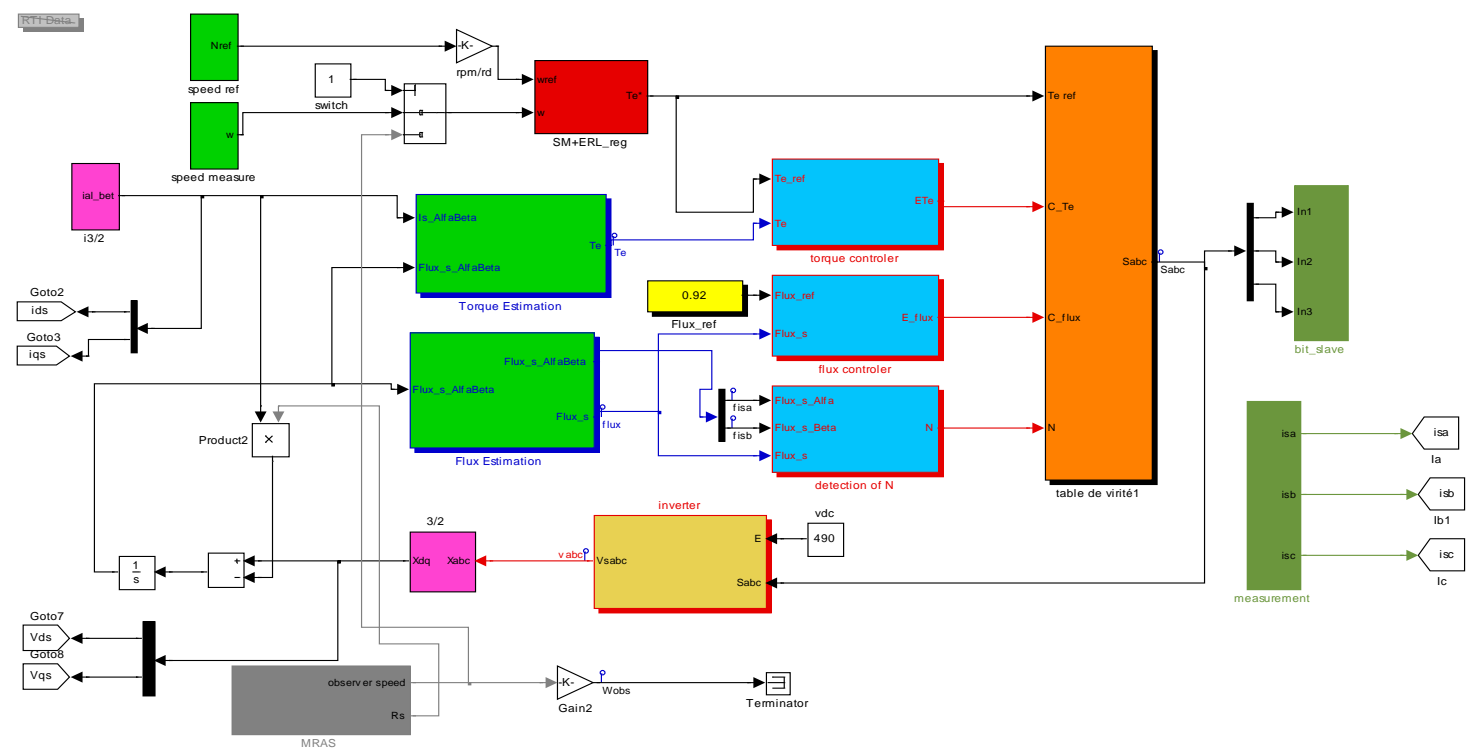

Figure 3. Control schema used in simulink and experimental tests

\section{EXPERIMENTAL IMPLEMENTATION}

The experimental test bench presented on the Figure 6 consists of a three-phase Y connected squirrel cage induction motor: $1 \mathrm{~kW}, 2880 \mathrm{rpm}, 230 / 400 \mathrm{~V}, 4 / 2,8 \mathrm{~A}$. The electrical and mechanical parameters are identified with the conventional methods which are cited in the table 1 . The motor is loaded by a DC $1 \mathrm{~kW}$ generator with resistive load; the control system is implemented on a dSPACE DS1104 card using the Matlab/Simulink RTI block. Sensors with Hall Effect are used to measure the stator phase currents, and the DC voltage, the motor is coupled with a 1024 pt incremental encoder for the rotor speed measuring. At first, a trapezoidal speed reference is used, changing between $-2000 \mathrm{rpm}$ and $2000 \mathrm{rpm}$, and loaded up to $50 \%$ of rating load by the DC generator. The low-pass filter is a good solution for reducing the chatter of the reference torque obtained from the SM controller, but the cut off frequency of this low-pass filter affects the performance of the regulators. Using small values reduces torque ripples reference but introduces more delay in the system dynamics. A frequency of $60 \mathrm{~Hz}$ was found to be a good compromise between torque ripples and dynamic response. In Figure 4 is snapshot of the experimental test-bench. The parameters of the machine are identified by conventional methods which are cited as following:

Table 1. The machine parameters

\begin{tabular}{llll}
\hline Variable & Value & Variable & Value \\
\hline Number of pole & 1 & Rotor inductance & $0.7490 \mathrm{H}$ \\
Stator resistance & $6.58 \Omega$ & Mutual inductance & $0.7209 \mathrm{H}$ \\
Rotor resistance & $5.81 \Omega$ & moment of inertia & $0.00207 \mathrm{~kg} \cdot \mathrm{m}^{2}$ \\
Stator inductance & $0.7490 \mathrm{H}$ & viscous friction coefficient & $0.000173 \mathrm{~N} \cdot \mathrm{m} /(\mathrm{rad} / \mathrm{s})$ \\
\hline
\end{tabular}




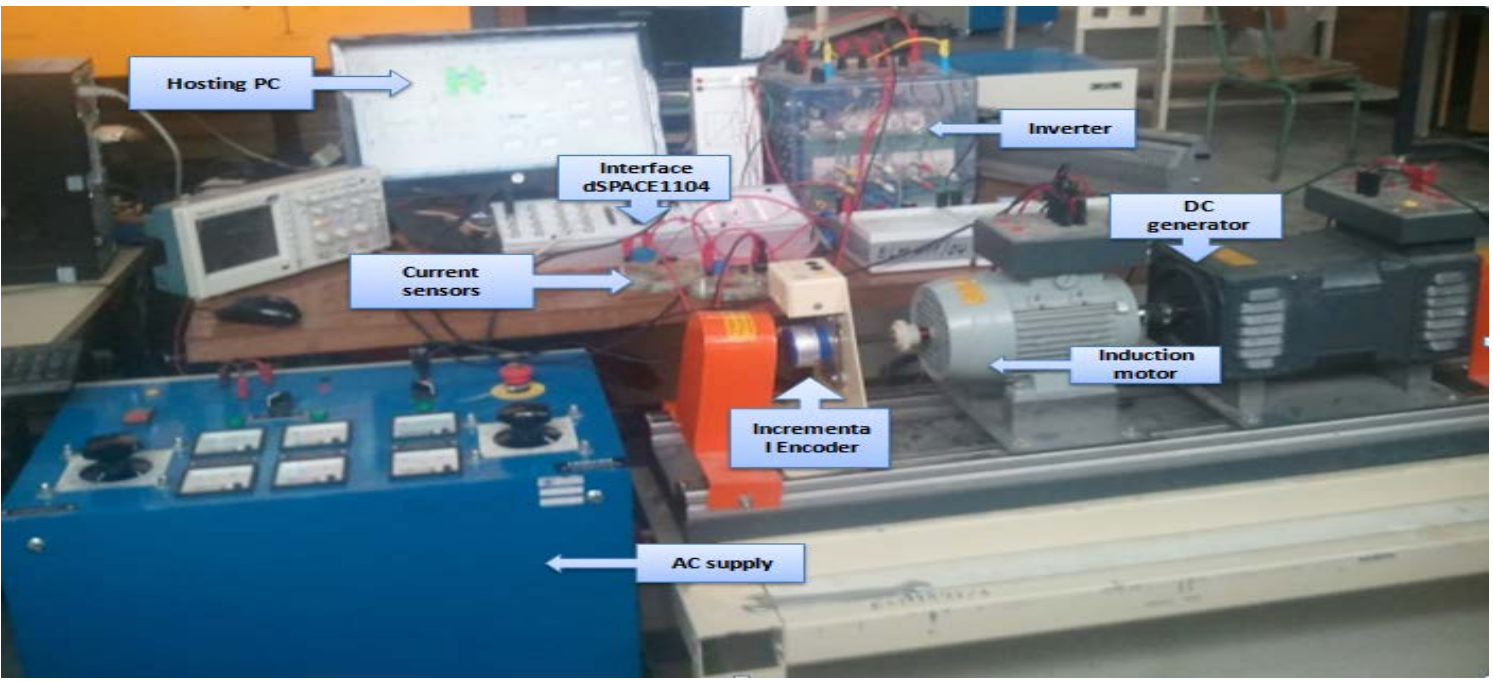

Figure 4. Snapshot of the experimental test-bench

The figures 5 are organized as follows: from the top down and from left to right are the wave forms of the reference $\left(N^{*}\right)$ and actual $(N)$ and observed $\left(N_{o b s}\right)$ rotor speed, the electromagnetic torque $\left(T_{e}\right)$ the stator phase current $\left(i_{s a}\right)$ and the rotor flux $\left(\varphi_{r}\right)$. On figures 6 and 7 the estimated stator resistance $\left(\hat{R}_{s}\right)$, and the estimated inverse rotor-time constant $\left(1 / \widehat{T}_{r}\right)$ are added.

\subsection{Study of the performance of the SM-DTC with MRAS-PI based speed estimation:}

The values of the PI regulator for speed estimator MRAS are: $\mathrm{Kp}=20,15$ and $\mathrm{Ki}=7076$, the sampling times used is Ts $=100 \mathrm{~ms}$ and solved by the Euler method. In Figure 5 is Graphic of the SM-DTC with speed estimation MRAS-PI.

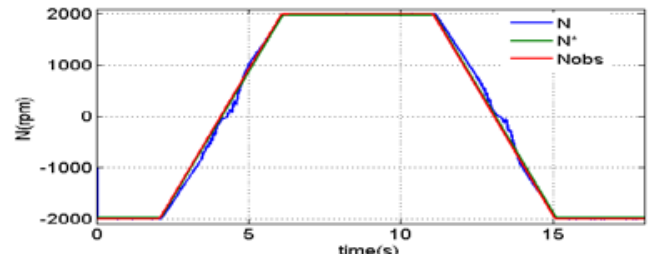

(a)

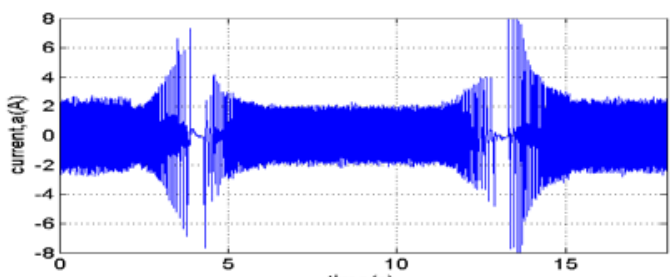

(c)

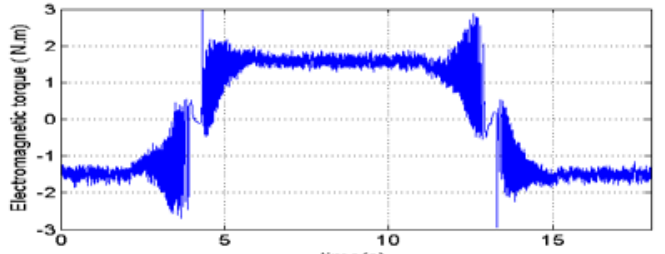

(b)

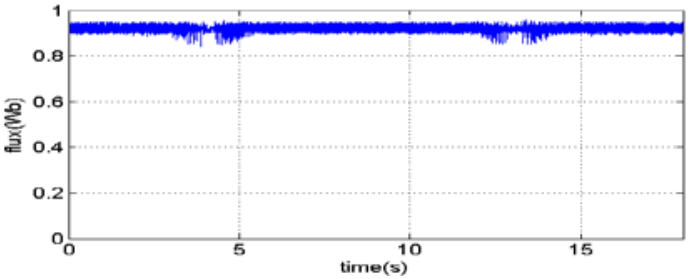

(d)

Figure 5. Graphic of the SM-DTC with speed estimation MRAS-PI

At 50\% load (Figure 5.), comparing with [6] where the author used a sliding mode controller for the regulation of the estimated speed by a MRAS technique, who found a problem of a small overshoot during the change of speed. Therefore, the ERL method integrate the controller sliding mode in this paper managed to solved the problem of the speed overshoot with a very good dynamic reply as shown in (5.a) where the actual speed $(N)$ exhibits the same behavior of that observed with negligible estimation error are follows the trapezoidal reference (up to $\pm 2000 \mathrm{rpm}$ ) instantly without overshoot or static error. But, a small divergence is seen when passing through zero, which is immediately corrected. The drive is stable even in the transient phase with little chattering in the torque (5.b) and the flux (5.c), thanks to the ERL-SM controller. 


\subsection{Study of the performance of SM-DTC with MRAS-PI based speed estimation and with ANN parameters estimation}

In figure 6 the machine is operating with $50 \%$ of the rated load. Compared to figure 5 we see the benefit of the online conjoint parameters $\left(\hat{R}_{s}, 1 / \widehat{T}_{r}\right)$ estimation by an artificial neural networks controller. First, to test the performences of this control at high speed, we used a trapezoidal reference speed varies between 2500 and $-2500 \mathrm{rpm}$. As shown in (6.a) the both estimated and measured speed following his reference instantly without any speed drop but with negligible static error that is not affected the stability or the dynamic response of the drive. The two figure (6.b), (6.d) shows compared to (5.b), (5.d) a very good improvement in the waveform of the stator flux and electromagnetic torque.it is clear that the chattring in these waveforms is remarkably reduced specially during the speed changing, this improvement mainly attributable to the proper definition of the estimated parameters by MRAS based ANN thechnique, which is very stable, and is not deteriorated even at the zero crossing as shown in (6.e) and (6 .f). Therefore, we can say that our method is one of the most effective Technics in the field of online parameters identification and the easier to implement compared to the other methods as in [19] where the author used a Pi controller for correcting the error between the reference and measure current for estimating the stator resistance. This method has shown good performances and large stability, but using the two filters is able to produce a response delay in the system. In Figure 7 is performance at low speed and zero speed.

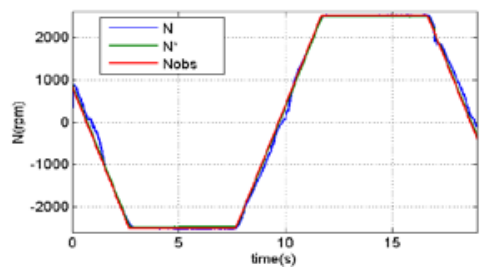

(a)

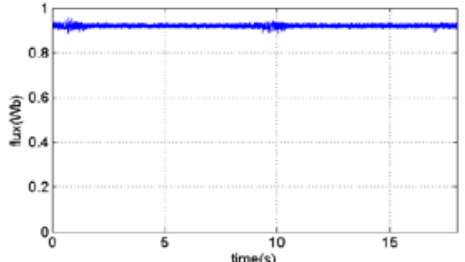

(d)

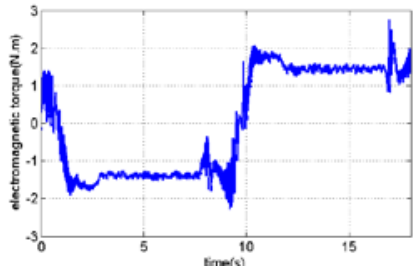

(b)

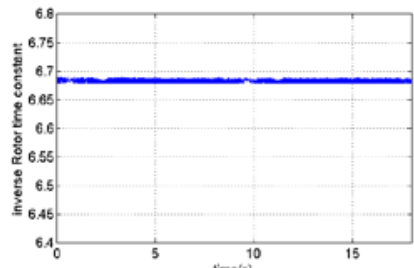

(e)

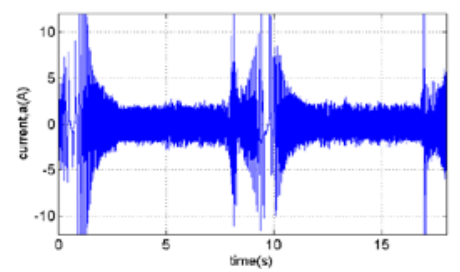

(C)

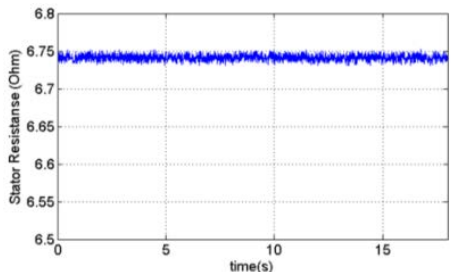

(f)

Figure 6. Performance of SM-DTC with speed estimation MRAS-PI with NN parameter estimation

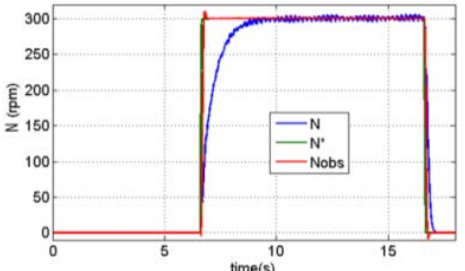

(a)

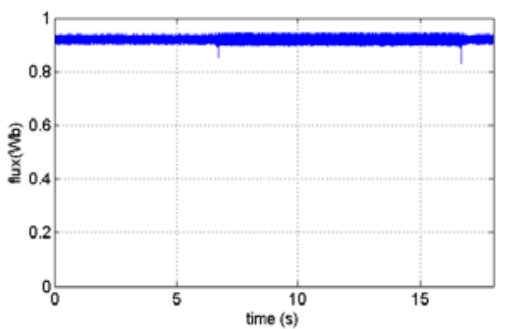

(d)

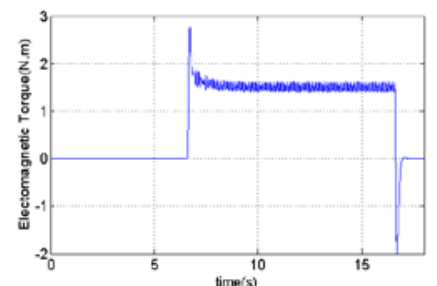

(b)

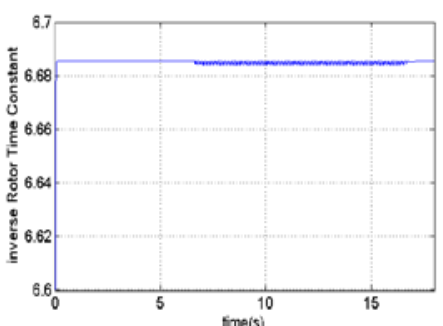

(e)

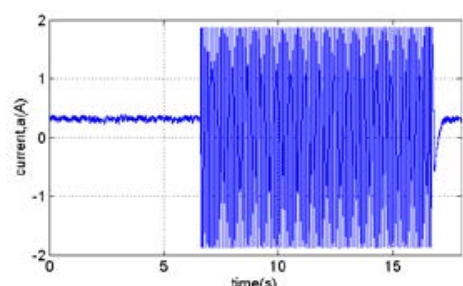

(c)

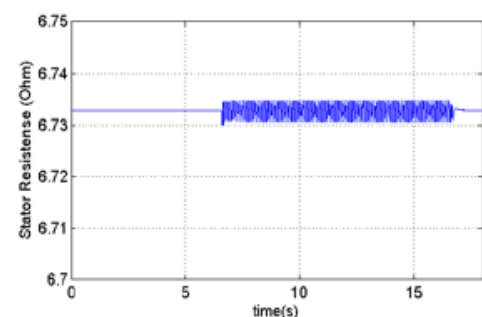

(f)

Figure 7. Performance at low speed and zero speed 
The stability of the system response at low and zero speed has been checked by a rectangular command starting from zero to $300 \mathrm{rpm}$ and with $50 \%$ of the rated load torque. by (7.a) and (7.b) we have seen a very good stability and dynamic response compared to [8] who realized the same work but with a mechanical adaptation with a Pi regulator for the estimation of the stator resistance, which fell into a chattering problém at low speed with an average response time. On the other hand, we have noticed in the estimated and actual speed also the estimated parameters presents digital noises which are notable from the pulsations in the speed figures; this is mainly related to the incremental encoder and dSPACE card resolution [20]. Nevertheless, at zero reference, the sensorless drive shows a good stability. The torque presents good dynamics, but oscillations occur as it can be seen in the waveforms.

\section{CONCLUSION}

In this article, we presented the implementation of a DTC control without a speed sensor using the rotor flux MRAS-based. Furthermore, we dealt with the resolution of the problems of parameters' variations by an online estimation of the stator resistance and the inverse of rotor-time constant. We changed the conventional PI controller by two types of non-linear regulators; a sliding mode controller with a reaching law method in the speed control, and a neural network controller in the online parameters estimation. We validated our studies with the experimental results that have shown good dynamics in both high and low speeds, and even at zero speed reference. Our next work will focus on a more stable MRAS method, and on generalizing all the adaptation mechanisms by a nonlinear artificial neural network controller.

\section{REFERENCE}

[1] Isao. Takahashi, Toshihiko. Noguchi, “Take a Look Back Upon the Past Decade of Direct Torque Control”, IECON. 23rd International Conference on Vol 2, Issue, 914 Nov 1997 Page(S): 546 - 551.

[2] J. W. Finch And D. Giaouris, "Controlled AC Electrical Drives”, IEEE Transactions On Industrial Electronics, Vol. 55, No. 1, Pp. 1-11, February 2008.

[3] Idris, N.R.N., Yatim, A.H.M., "Reduced Torque Ripple And Constant Torque Switching Frequency Strategy For Direct Torque Control Of Induction Machine”, Applied Power Electronics Conference And Exposition, Page(S): 154 - 161 Vol.1, 2000.

[4] M.Boussak, K. Jarray, "A High-Performance Sensorless Indirect Stator Flux Orientation Control Of Induction Motor Drive”, IEEE Transactions On Industrial Electronics, Vol. 53, No. 1, February 2006.

[5] M.Cirrincione, G. Cirrincione, "An Enhanced Neural MRAS Sensorless Technique Based On Minor-Component-Analysis for Induction Motordrives”, IEEE ISIE 2005, June 20-23, 2005, Dubrovnik, Croatia.

[6] Gouichiche Abdelmadjid, "Sensorless Sliding Mode Vector Control of Induction Motor Drives", International Journal of Power Electronics and Drive System (IJPEDS) Vol.2, No.3, September 2012, pp. 277 284.

[7] C. Schauder, "Adaptive Speed Identification For Vector Control Of Induction Motors Without Rotational Transducers”, IEEE Transactions On Industry Applications, Vol. 28, No. 5, Pp. 1054-1061, September/October 1992.

[8] Zicheng Li, "Rotor Speed and Stator Resistance Identification Scheme for Sensorless Induction Motor Drives", TELKOMNIKA, Vol.11, No.1, January 2013, pp. 503 512.

[9] J. Holtz And J. Quan, "Drift And Parameter Compensated FLux Estimator For Persistent Zero Stator Frequency Operation Of Sensorless Controlled Induction Motors”, IEEE Transactions On Industry Applications, Vol. 39, No. 4, Pp. 1052-1060, July/August 2003.

[10] V. I. Utkin, “Sliding Mode Control Design Principles and Applications to Electric Drives”, IEEE Trans. Ind. Elect. Vol 40, 1993, Pp. 23-36.

[11] S. Bolognani, L. Peretti, And M. Zigliotto, "Parameter Sensitivity Analysis Of An Improved Open-Loop Speed Estimate For Induction Motor Drives”, IEEE Trans. Power Electronics, Vol. 23, 2008, Pp. 2125 - 2135.

[12] Veran Vasic', Slobodan N. Vukosavic And Emil Levi, “A Stator Resistance Estimation Scheme For Speed Sensorless Rotor Flux Oriented Induction Motor Drives”, IEEE Transactions On Energy Conversion, Vol. 18, No. 4, December 2003.

[13] Zerikat. M., Chekroun.S, “A Robustmras-Sensorless Scheme Based Rotor And Stator Resistance Estimation Of A Direct Vector Controlled Induction Motor Drive Methods And Models In Automation And Robotics (MMAR)”, 2011 16th International Conference On ,2011 , Page(S): 151 - 156.

[14] Gadoue, S.M., Giaouris, D., Finch, J.W., "A Neural Network Based Stator Current MRAS Observer for Speed Sensorless Induction Motor Drives", Industrial Electronics, 2008. ISIE 2008. IEEE International Symposium On, Vol., No., Pp.650, 655, June 30 2008-July 22008.

[15] M. Grzesiak and B. Ufnalski, "Neural Stator Flux Estimator with Dynamical Signal Preprocessing", In Proc. IEEE AFRICON, 2004.

[16] A. Ba-Razzouk, A. Cheriti, G. Olivier, And P. Sicard, "Field Oriented Control Of Induction Motors Using Neural Network Decouplers", IEEE Transactions On Power Electronics, Vol. 12, Pp. 752-763, 1997.

[17] Ingh, B., Jain, P., Mittal, A.P.; Gupta, J. R P, "Neural Network Based DTC IM Drive for Electric Vehicle Propulsion System", Electric and Hybrid Vehicles, 2006. ICEHV '06. IEEE Conference On, Vol., No., Pp.1,6, 18-20 Dec. 2006. 
[18] I Fallaha, C.J.; Saad, M.; Kanaan, H.Y.; Al-Haddad, K., "Sliding-Mode Robot Control With Exponential Reaching Law," Industrial Electronics, IEEE Transactions On, Vol.58, No.2, Pp.600,610, Feb. 2011.

[19] N. Panneer selvam ' On-Line Stator Resistance Tuning of DTC Control CSI Fed IM Drives” International Journal of Power Electronics and Drive System (IJPEDS) Vol.2, No.2, June 2012, pp. 225 231.

[20] T. Orlowska-Kowalska, And M. Dybkowski, "Stator-Current-Based MRAS Estimator for a Wide Range Speed-Sensorless Induction-Motor Drive,” IEEE Trans. On Ind. Elec., Vol. 57, 2010, Pp. 1296-1308.

\section{BIOGRAPIES OF AUTHORS}

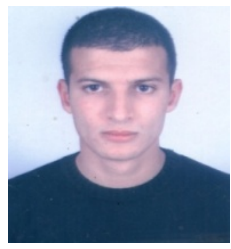

Legrioui Said: was born in Mila, Algeria in 1989, he is a Ph.D student and member at electrical engineering laboratory of Constantine (LEC) with Master of management and transformation of Electrical Energy from University of Constantine 1 Algeria (2013). He obtained Licence Degree in control and transformation of Electrical Energy from Institute the sciences of Technology in 2011. His researches are in fields of control systems, power electronics, electrical drive and parameter identification.

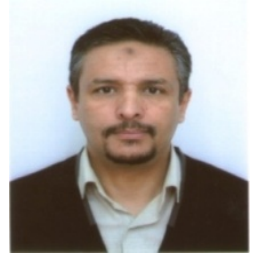

Rezgui Salah Eddine: was born in Constantine, Algeria in 1971. In 2015 he received the Ph.D. degrees in Electrical Engineering at the University of Mentouri's brothers of Constantine. Currently he is working as lecturer and he is researcher member in Constantine Electrotechnics Laboratory. His research interests include modern control theory applications, electric machines, power electronics and drives.

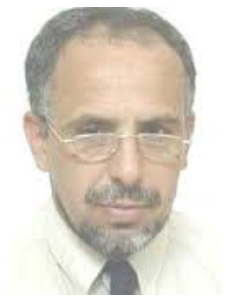

Benalla Hocine: was born in Constantine, Algeria in 1957. He received the Ms.C., and Doctorate engineer degrees in power electronics, from the National Polytechnic Institute of Toulouse, France, respectively, in 1981, and 1984. In 1995, he received the Ph.D. degrees in Electrical Engineering from university of Jussieu-Paris VI; France. Since 1996, he is currently professor of Electrical Engineering in Department of Electrical Engineering at Constantine University Algeria. 